\title{
An MA degree in reflective social practice: Developing a social sensibility
}

\author{
Allan Kaplan \\ The Proteus Initiative
}

\begin{abstract}
"... the one thing that we do not see, when we look out at our world, is the way and the how we see our world.... This is worth staying with for awhile, for it concerns us deeply as activists; the hearth-place of freedom, of our very humanity, may lie just here, in this realm that we seldom even think about."
\end{abstract}

Allan Kaplan and Sue Davidoff - A Delicate Activism

A couple of nights ago I went to have dinner at a friend's house overlooking the eastern seaboard of Cape Town (a vast bay ringed by mountains, open to the south and the Antarctic - False Bay). Mid-summer, the evening hot and balmy - sandals and t-shirt weather. Moon rising across the bay, the sea below us silvered, the house candle-lit; I went about the small house barefoot, having slipped my sandals off earlier. When it came time to go, I went to find my sandals in the moon and candle-darkened house, found them eventually, started putting them on - they had a strange feel to them, one went on easily, the other not - suddenly I realised that they were separate sandals: one each from two pairs that lived in my bedroom at home side by side. I went to show Sue - my partner in life and work - the crazy thing that I had done. When still at home, I had put on two entirely different sandals, one ancient and leather and worn and beloved, the other synthetic and new and designed exclusively for hiking hard trails. And I had noticed nothing - yet I love the one and slightly resentfully endure the other. For days after the event, Sue found it difficult to stop laughing; her laughter gave her stomach cramps - paying attention, accurate observation, being present...? Myself, I felt soul-naked; was I perhaps counterfeit, nothing more than a quack?

You might question, then, what this Masters program of which I will write has to do with mindfulness (the theme of this edition of the journal). Well, fortunately, it does not foreground Mindfulness as a specific protocol or technique or trademarked entity - though this doesn't let me off the hook, for it certainly foregrounds presence, presence of mind, being mindful at all times. But it recognises too, very much so, our beleaguered humanity; that we stumble, sometimes embarrassingly. And it asks, not that we be perfect, but that we uphold irony as a virtue, and foreground reflection as the only valid path that may lead us through the trackless wastes of social complexity which we seek to decipher and render transparent. This is a Masters in reflective social practice; we see a reflective practice as foundational for all practices.

Some lines from the program brochure read:

We work with what it means to see social situations as alive. We cannot find any frameworks for resolving social problems. We encourage participants to develop new ways of understanding the world and their work, and particularly to develop new faculties to read situations and engage in practice. To develop greater attention, awareness and openness. We understand that different contexts and cultures require subtly different ways of working, and that there is no blueprint for all.

What may it mean, though, to "see social situations as alive"? About two years ago we were sitting at a family dinner in Wellington, New Zealand. We had been invited by the parents (who had been beloved participants on workshops that we had run in New Zealand) to meet this wonderful, rambling, intelligent and articulate family. During the course of the evening, the four children, ages ranging between 12 and 23, asked us - it must have been one who spoke, but they had a remarkable way of maintaining their collective familial accord through a practice of strong individuality - what the Masters program was about.

Put on the spot like this, we are always flummoxed for words; both the world, and the program, are too

Correspondence concerning this article should be addressed to Allan Kaplan, The Proteus Initiative. email: alkaplan@mweb.co.za 
complex for this kind of dinner table question put by the young! And then I said - because there are no inexperienced youth, and these were particularly wise souls asking the question - that everything that is alive is in a state of constant movement, continual becoming, every person and every situation, and this movement is taking place through everything else; but that we tend to see our world as 'things' that are 'static', with boundaries and borders that serve to "end the thing and separate it from other things" (despite which we speak glibly and easily of complexity). Also, that every living being has an inside as much as an outside, and that in fact it proceeds - as it were - from inside towards outside, the visible 'form' or 'product' emerging from the invisible "energetic process, or living idea" that gives rise to it.

Yes, they said. They understood - and we could see immediately that, startlingly, they really did understand, with an immediacy that was profound.

Well then - we (us humans) needed to find a new way of seeing, to be able to really see 'aliveness', or 'alive beings' on their own ground, not as material and fixed things only but also as porous beings which flowed into and out of other porous beings, informing and influencing them whilst being informed and influenced by them, yet each and all still maintaining their individual identities even as they changed and interwove one with the other. And the world in which we live, the world as context, this world arises out of these interactions, even as it forms their ground. Yes, they answered, they understood; and again we saw that they really did understand.

So anyway, I said - this is what the Masters program is working with; their excitement was boundless.

Let me come at this from a different place for a moment. It really becomes about how we see. The way we see is the world that we see. The way we see creates the world that we see. This is the phenomenological point of departure out of which this program arises. Can a practice that foregrounds observation play a healing role in the world? - this question is central to the Masters program. How do we develop a way of seeing and intervening that can see wholeness, that can observe aliveness, that can 'enter within'?

With this newly minted consciousness, we draw on a range of ideas and influences that have helped shape our work, from contemporary, cutting-edge ideas in the social sciences to thinkers and strands of wisdom that have significantly influenced humanistic approaches to social practice over many centuries. We draw particularly from the practices indicated by a Goethean phenomenology, traditional and contemporary contemplative and reflective practices, and the implications for practice in the social field arising from the understandings developed by the 'new sciences' (from quantum theory to complexity) and by holistic approaches inspired and grounded through observation of living process".

Social processes are best observed, reflected upon, understood and engaged with through open observation and open conversation, rather than dividing and compartmentalising and instrumentalising things too soon. It is not techniques or models or frameworks or information or even knowledge that will see us through, but the development of faculties - as Goethe put it, the development of organs of perception - that will gradually render us human enough to enable a more human world to emerge.

In pursuit of our intentions, this program focuses on the development of such faculties. It promises, not a philosophical phenomenology but the practice of phenomenology. Its spirituality lies in this - that it seeks to see the inner idea in every moment of outer reality. Its practice works towards the development of a sensibility for life through an embodiment of the 'open methodology' developed as phenomenological practice by Goethe - a disciplined and intentional approach to reading the living world of nature, adapted for working within the social sphere. And, so that our means are also and at the same time our ends, we work with intellectual and 'holistic (or organic)' consciousness simultaneously, we work with action (change practice) and reflection simultaneously, we work with academic and professional emphases simultaneously, we work with 'reading (situations)' and writing simultaneously, and we work with self-observation and world-observation as paths that take each further into the realm of the other.

We achieve this through working with six interwoven modules plus a mini-dissertation, spread over just under three years and including six residentials of nine days each. The modules read as follows.

\section{Social development frameworks and approaches}

In this module we explore various theoretical approaches to social practice, drawing from current dominant social theory whilst also generating an understanding of an alternative approach that has as its foundation holistic or organic thinking. Our intention here is never merely intellectual content but the ability to think with intelligence and heart. 


\section{Reading and making meaning of social situations}

We see this module as foundational for the program, the module around which all the other modules revolve. We present approaches and practices where students are given experience and understanding of how to read - and make meaning of - social situations so that through this understanding, this reading, they attain a very real sense of appropriate ways of actively engaging with the situation (guiding from the inside rather than imposing from the outside).

\section{Researching social practice}

This module too is foundational for the program - a unique aspect of this MA program brings together both the academic and the professional dimensions of reflective social practice. We have therefore emphasised the balance and the relationship between theory and practice, and developed creative ways of building this link into an MA degree.

\section{Self in practice}

Since this program is envisaged as a journey of becoming and transformation, and since - in our understanding - each person is their practice, it is important for students to deepen their understanding of themselves, and to stretch their inner worlds. We want them to understand that their practice is as deep and insightful and skilled as they are as human beings.

\section{Frameworks and principles for professional practice}

In this module we look at the principles which ensure ethical professional practice, which enable students to develop a sharpened sense of their own professionality, to build rigour and clarity of purpose into their professional practice, to acquire a sense of quality within which they might judge their own work according to their own professional and personal values, and to practise accordingly.

\section{Morphology and organisation}

Most social practitioners do their work either working in, or through, the field of organisation. How practitioners work with organisations depends to a large extent on their understanding of the development processes that result in organisations functioning the way they do. This module explores the morphology of organisations seen as holistic living organisms - as opposed to seeing organisations as mechanisms or mechanical systems.

The social and ecological crises in our world are deepening, beyond the capacity for technical and instrumental responses to find a way through. Engaging with the problems we face in the world today requires an exercise of imagination and creativity that is often stifled by the driven simplicities of dominant practice. This program gives space and support to explore and develop a grounded, aware, engaged and imaginative interpersonal practice. The program is highly relevant for anyone working around social issues, who wants to work differently and contribute imaginatively and with sensibility to our social future.

The program offers the possibility to understand and work with more attuned, open and organic approaches to social understanding and practice. To work in ways that are respectful of the complexity and true nature of the challenges we face in the social field. We offer a program that seeks to provide an enlarged picture of the human being (and the world we inhabit). Recognising that the world we inhabit is socially and ecologically impoverished, we choose to design a program that will open people's horizons - both to themselves and to their responsibilities in terms of intervening creatively into such a world.

A student on the current program attests: "This Masters program lives inside of me as the generative positive change it intends to see in the world...As I have immersed myself in it, I have witnessed this change process unfolding through me and around me, in my work and at all the edges of my life. It feeds my life forces in a way that makes the substantial time commitment and consistent rigorous work it takes seem effortless." (Tanya Layne, Deputy Director - Learning Network, SA National Biodiversity Institute.) 


\section{PERSONAL PROFILE}

Allan Kaplan is a development practitioner, teacher and writer. He is the author of The Development Practitioner's Handbook and Artists of the Invisible. He works internationally out of The Proteus Initiative (based in Cape Town, SA), founded as a vehicle for developing the organic and holistic methods of J.W. von Goethe into a new understanding and approach to the sphere of social renewal. His work is an attempt to realise the full consequences of true participation, of socio-ecological complexity, and of an emerging consciousness which holds freedom and responsibility as a generative polarity in the quest for wholeness.

For more detailed information about the Masters program, you can visit www.proteusinitiative.org 